\title{
Present Evaluation Method of Examination: A Critical Survey
}

\author{
Dr.Asim chatterjee, Dr. Laxmi Rani \\ Post doctoral research scholar B.R.A.Bihar University, Muzaffarpur \\ Assistant Professor M.S.K.B.College, B.R.A.Bihar University, Muzaffarpur
}

\begin{abstract}
It has been said that the system mostly produces robots who possesses an amazing capacity for storing facts and churning them out at the press of the right button. Qualities like independent thinking, problem solving ability, initiative leadership skills and social competence fall by the wayside as getting high grades becomes their only goal.

My present article tried to drive at the crux of the problem that whether present day evaluation system in examination is following the set norms of real evaluation or not. I have discussed in my paper that how the present education system is like training of monkeys to read and write. There is nothing creative here, except boycotting and vomiting. The students are unable to comprehend something, no skills are improved. Evaluation is something more than the examination. It includes quantitative description, qualitative description and value judgement, but in the examination we never do the qualitative assessment nor the value judgment. In my submission I have focused attention on teacher - pupil relation also because effective use of communication skill makes the teaching effective and conveys the knowledge of the teacher to students. It is the students who are a better source of information about the communication skills of a teacher than anyone else. Hence evaluation system should be designed on
\end{abstract}

\section{THE PAPER}

Before writing about the crux of the topic, it should be cleared that what 'Evaluation', the word particular is carrying the significance? Ultimately the primary question rises that what is evaluation? Evaluation offers a way to determine whether an initiative has been worthwhile in terms of delivering what was intended and expected. However, good evaluation can also answer other important questions. Most evaluation falls into one of the three categories:

(i) Process based-

(ii) Outcome based-

(iii) Impact based-

$\underline{\text { Page }-2}$

(i) Process based evaluations are used to understand how a programme works and delivers its results.

(ii) Outcome based evaluations are used to measure any change immediately after programme implementation and to establish that these changes have occurred in response to the intervention being evaluated.

(iii) Impact based evaluation is by far the most complex and difficult to carry out, the impact based evaluations examine the long term effects of an intervention on participants. The most successful type of impact based evaluation tracks effects over extended period of time, rather than simply examining conditions immediately "before" and "after" the intervention has been implemented.

The million dollar question arises from the above theory of evaluation that whether these rules have been taken into consideration while evaluating the responses of our students in today's examination- evaluation process. An honest answer to this is a big 'NO'. In our today's education system, which is by and large a legacy left by the British rulers suitable for them at that time to produce 'babus' in govt. offices for executing all the clerical works.

In the present practice of schools and colleges and universities and other educational institutions not to hand over the answer books of the students at the time of declaring their results of examination. The completed answer books of the students of term and half yearly exams are being shown to students and again taken back by the educational institutions. The answer books of competitive examinations are not even shown to students/candidates and

$\underline{\text { Page-3 }}$

finally return to them does not arise. If evaluated answer books are finally handed over to the students along with the final result, it would be fruitful for them to know their short comings while answering the 
questions in the examinations and they would be able to enhance their knowledge and also show better performance in next examination.

The present evaluation method of examination particularly in Indian education system has become completely deviated from the set rules of evaluation. As it exists today, does not at all assess the real worth and intelligence of the candidate. If same answer is judged by the two different examiners, we find a lot of difference. One examiner may be liberal and another may be meticulous one, the way of marking differs a lot.

The present day evaluation system in examination is nothing but a matter of chance factor, no certainty or reliability can be placed. Most of the students suffer from examination phobia, as the date of examination draws nearer, the students start becoming nervous. Many times, his nervousness so overpowers him, that even his best learnt lessons seem evaporated from his mind. Many times the question paper gives him utter shock, whatever the topics he left out, thinking unimportant or unworthy of appearing in the papers, are there in the paper and topics of important find no place in the paper.

\section{$\underline{\text { Page-4 }}$}

The existing examination system and procedure of judging one's ability is so unnatural and faulty that a mediocre student can secure distinction marks and an intelligent may cut a sorry figure. Moreover in the present evaluation system excepting the question paper of objective type, only cram work is useful. One who possesses good power of cramming, facts and texts, secure good marks rather than an intelligent, who could not cram but analyse in a proper manner.

Our education system is universally criticized for a number of gaps in our examination system. It is criticized for not keeping pace with the demand of the outside world for not being scientific and comprehensive for not considering the practical skills required for good adjustment and for its traditional methods of measurements. Time and again various committees and commissions have tried to address the inherent malice in the examination system but for our conventional thinking nothing fruitful has resulted in this direction. NCF 2005 also emphasized the need for reforms in present examination system by making them child friendly and stress free. Hence it is felt that it is high time that we have a serious look into the issue and bring about some changes taking off its demerits for making examinations an important tool in assessment of child. As part of this the SCERT has conducted a number of meetings, seminars and workshops on examination reforms. The government of A.P.issued G.O.M.S. $122 \mathrm{dtd}$.5.10.2005 and constituted a core committee to examine the issues of introduction of grading system and other reforms in examinations. In continuation of this a meeting was organized in SCERT on 6.12.10 involving the experts from the state and national levels.

\section{Page-5}

Our entire education system is centered around examinations. Evaluation means to conduct the examination and to give marks and ranks to students. Student's knowledge is often limited to by hearing and reproducing the same in the examinations. Their innate talents are not recognized; instead their capability in writing examination is being tested. It is restricted to only by hearting or rot memory. There is no uniformity in evaluation, different types of evaluation systems are prevailing in different boards i.e. government, ICSE, CBSE etc. There is no flexibility in the conducting of tests. It is rigid board examinations are only helping in classifying students as meritorious and slow learners; that is in turn pass/fail. This leads to unhealthy discrimination. The tests and examinations conducted at present are only testing the memory power of the students; they are not measuring the higher order skills of learning, like analysis, synthesis and problem solving. The examinations are mechanical. Correcting and posting of marks is done routinely. There is no scope for remedial teaching and testing to know how far a student is lagging behind. Examinations are not helping in assessing the all round development of the student that is co- curriculum social personal qualities and health status and also they are not helping to testify their level of competency.

Examination means the test of a student's knowledge in prescribed subjects. An examination creates a sort of care in students to prepare their studies sincerely. Examinations may be of various types such as oral, written and practical. In lower classes oral test is conducted in lieu of written test since students do not have the ability to write at that age. In higher classes of course written test is invariably conducted. In science and technical studies, practical examinations are conducted.

\section{Page-6}

Examination ascertains the proficiency of a student up to a certain limit. It induces students to prepare well in the subjects given to them. But by examination the real talent of students cannot be fathomed. The research minded scholars have been found not to have performed well in the stereotyped examinations. 
Whereas a mediocre student may perform well in an examination by preparing some selective topics, a meritorious student may not fare better comparatively. The reason is questions are set from a few topics. Instances of great men like Winston Churchill, Mahatma Gandhi, Albert Einstein and Eddison may be cited in this respect. Our examination compels students to prepare for those topics or for which students are not interested. Great minds cannot be tested by the prevailing evaluation of examination system that is defective. The term examination makes a student unnecessarily nervous as mentioned earlier in the present paper.

Examinations are thought as a test of the ignorance of students. But it is not justifiable. The present system of examination encourages the habit of cramming. No step has yet been taken to rectify the defects so far. We find that a student fleets his time carelessly for the whole year without study as reading for a few days before the day of examination enables him to pass the examination. They pass the examination just by getting by heart some selective topics. Another method adopted by students now a day for passing is by copying. The examination encourages idleness, copying and carelessness, for eradicating such evils the progress of a student should be judged not by the final result but by taking into account the result of several examinations conducted by various

\section{Page-7}

examiners. Otherwise dull students would be able to show their brilliance whereas good and sincere students would feel neglected and helpless.

There is a difference of judgment in awarding marks in essay type questions by different examiners. Examinations however cannot be avoided altogether. The question papers should be designed so as to test the overall aspect of a student. By such changes, the drawbacks of evaluation and in the system of examination can be brought down up to a certain extent.

To follow what is espoused in RTE 2009. Evaluation should have a broader framework and it should not be limited to examinations alone. Exams should include student's displays, projects, seminars, collection of information and reports. The examinations should not create fear or stress to the student. Evaluation should be continuous and comprehensive and it should be the part and parcel of daily teaching learning process. It should not restrict to rot memory. When construction of knowledge becomes primary in curriculum the evaluation should be continuous and comprehensive i.e. along with the teaching learning process. The assessment should be based on day to day activities. The examinations should not be restricted/limited to writing but extended to assessment tools like observation,discussion,note taking,recording,collection of opinions etc. the assessment should not only be teacher based but also on peer groups, parents and others.

The day to day teaching learning process depends on the experience of the children. So student's participation should be there in the teaching learning process. Their knowledge,

Page- 8

understanding and their application skills should be assessed. Therefore the teachers can record this information in their teacher's diaries and manuals. There should be coordination among learning evaluation and objectives. Students note books, their written exhibits and all their other objects should be treated as assessment tools. For self evaluation of students, quality remarks check - list should be utilized. There is no need to test all the teaching items taught in the classroom. But only some important items must be checked comprehensively at random. After evaluation action plan should be prepared for improvement of the child.

Examinations are the part of the evaluation system. Instead of three terminal examinations, two should be conducted. A test is to be conducted after completion of every unit; with this we will know the children's achievements and their level. It helps to know the competency level of the child for remedial teaching. The most important item in the test is the nature of questions. They should be above the level of rot learning. The open ended questions which allow the students to think and write and express their views on their own should be given importance. To evaluate these questions the indicators should be prepared. Entrance examinations and board examinations are to be abolished. Teachers are to be encouraged to prepare their own question - papers to conduct examinations. In service training programmes should conducted for teachers to develop their ability to make question papers innovatively. They must be given adequate skills to prepare question banks.

\section{Page-9}

Teaching is a unique profession. The process of evaluation in examination does not only centered to the output of students that what they have memorized to pass out in the examination but it is rather an evaluation of teacher also, who toiled hard throughout the year for his /her pupils to make them a better enlightened citizen of the society. Teaching is a profession- it is not a calling, it is not akin to being priest, in teacher's entire career, he in some way, evaluate what he produces. This evaluation process helps him to do his job in a better way. 
Recently, after many discussion and table talks CBSE has introduced "Continuous Comprehensive Evaluation (CCE)". In the past system, the students undergo severe stress and strain in the wake of competition. All parents want their child to be in the top ranking, that leads the child in strain. Everyone wants their children to become doctor, engineer, manager etc. There are lakhs of profession but leaving all those opportunities all are running behind these three options which is the deciding factor for high expectation. Making use of this huge demand of those courses, the private schools and universities earning huge money. If the children scores low marks and does not fulfilling their parents' wishes or expectations then their relation breaks up. Many children committing suicide attempt only because of getting low marks or failing in the examination. There is a question raised by the eminent educationist that how a student scores 71 is better than those scored 70 ? Is there any yard stick to exactly measure the mental level of a child? The answer is definitely 'NO'. The numerical marking is largely affected by subjectivity. Subjectivity is nothing but if an answer book is given to three examiners then after evaluation you will get three different marks. This is called subjectivity. In this condition whose evaluation is correct, no one can answer for this question. So, the educationist suggested the grading system for evaluating a child. Considering all the above aspects it is become

\section{$\underline{\text { Page-10 }}$}

necessitate to introduce the new CCE which is really a reform in Indian system of education. This new system of evaluation CCE follows three domains to be taken into consideration for evaluating a child:

(i) Cognitive Domain-

(ii) Affective Domain-

(iii) Psycho motor Domain -

(i) Cognitive domain- The cognitive domain deals with the mental level of a child. In the past system of education, cognitive domain is given more importance in comparison with other domains. All other two domains are simply neglected. If a child good in academics then he/she will be declared pass otherwise the child gets failed. Every child born with its own capacity to deal with different areas. So, evaluating a child in only one area is totally obstacle.

(ii) Affective domain-In the past system of education there is no such scope to assess a child over this affective domain. This domain mainly deals with the social and emotional skills of a child. How a child making relationship with their teacher, friends and parents. It also envisages their emotions such as anger, patience and happiness etc.

(iii) Psycho motor domain- In the past system we do not have any scope to assess a child over this psycho motor domain. This domain mainly deals with the action skills such as drawing, making graphs, making useful things etc. This domain is also not given equal importance as the cognitive domain.

\section{Page-11}

In ancient system of education in India rather everywhere the results were not in form of pass or fail. The student was given full opportunities to learn not only academics but all the aspects of life. After a particular duration he was sent back to live without pass fail result or degree. One has to prove himself by performance and not on the basis of marks gained in an instant examination.

In higher studies where innovative thinking and subsequent research is the primary requirement, there also the situation is pathetic rather more dismal if compared to lower levels. Students are following the same old beaten tracks of mugging up the answers of guess questions and vomiting it on the copy of exams and pass out with average good marks. Teachers have become so tired of the same monotonous way of evaluating, that they hardly look for the innovative thought provoking answer. In this context I wish to cite an example from the movie Three Idiots, the central theme of the movie is innovating and research oriented answer. We have seen that the chief protagonist is advocating in favour of innovation of answer in the copy, but for this teacher-pupil relation in the class room throughout the year is very important. It is ultimately the onus of the teacher to encourage the students to think independently and with a new angle in his own way at the answers of the prescribed syllabus.

The responsibility also goes to the university administrations, who are the policy makers. Evaluation of examination copy at the higher level is the most sensitive and important work after examination. The work of evaluation should not appear loathsome to the teachers, adequate numbers of experienced teachers, proper sub staffs, meticulously prepared tools for checking the copies should be provided. Evaluators as well as the examinee both should be encouraged by announcing awards/rewards for best innovative answer or best evaluator of the session like.

$\underline{\text { Page-12 }}$

Recently the head of Scientific Advisory Council to the Prime Minister,C.N.Rao has written a letter to the Prime Minister that India has exam system, not education system, when will young people stop taking exams 
and do something worthwhile? IIT exams have the reputation of being difficult and purposeful, but they have also had a negative effect on young minds. Young people suffer so much to succeed in these entrance exams, and in the process lose excitement in education itself. Can anybody assess that the lakhs who don't make it across the IIT gates, get exhausted and can't perform as well as young people with fresh minds.

Evaluation in the examination is of the supreme importance in the whole gamut of education system. Evaluation of present fully depended on a set rule; neither the evaluator teacher nor the authorities are interested to try something new. Mere awarding marks and preparation of lengthy tabulation sheet does not finish off the responsibility of a teacher. Scientific temperament of a student must be identified based on his answers on examination copies. If the system adopts this, many potential researchers having possessed requisite research skill set may come forward to undertake research activities.

\section{References:}

[1]. Reform in Examination system in India - Sulekha Education, New Delhi, 2010.

[2]. International centre for Alcohol Policies Journal.......google.net.in.

[3]. India Education Review, New Delhi, 2013........google.net.in

[4]. The PEBC Network - Education News, Colorado, USA, June 72011.

[5]. South East Asian Journal of Medical Education Vol.2 no.2, 2008. 